Figure S3

\title{
Bladder Urothelial Carcinoma
}

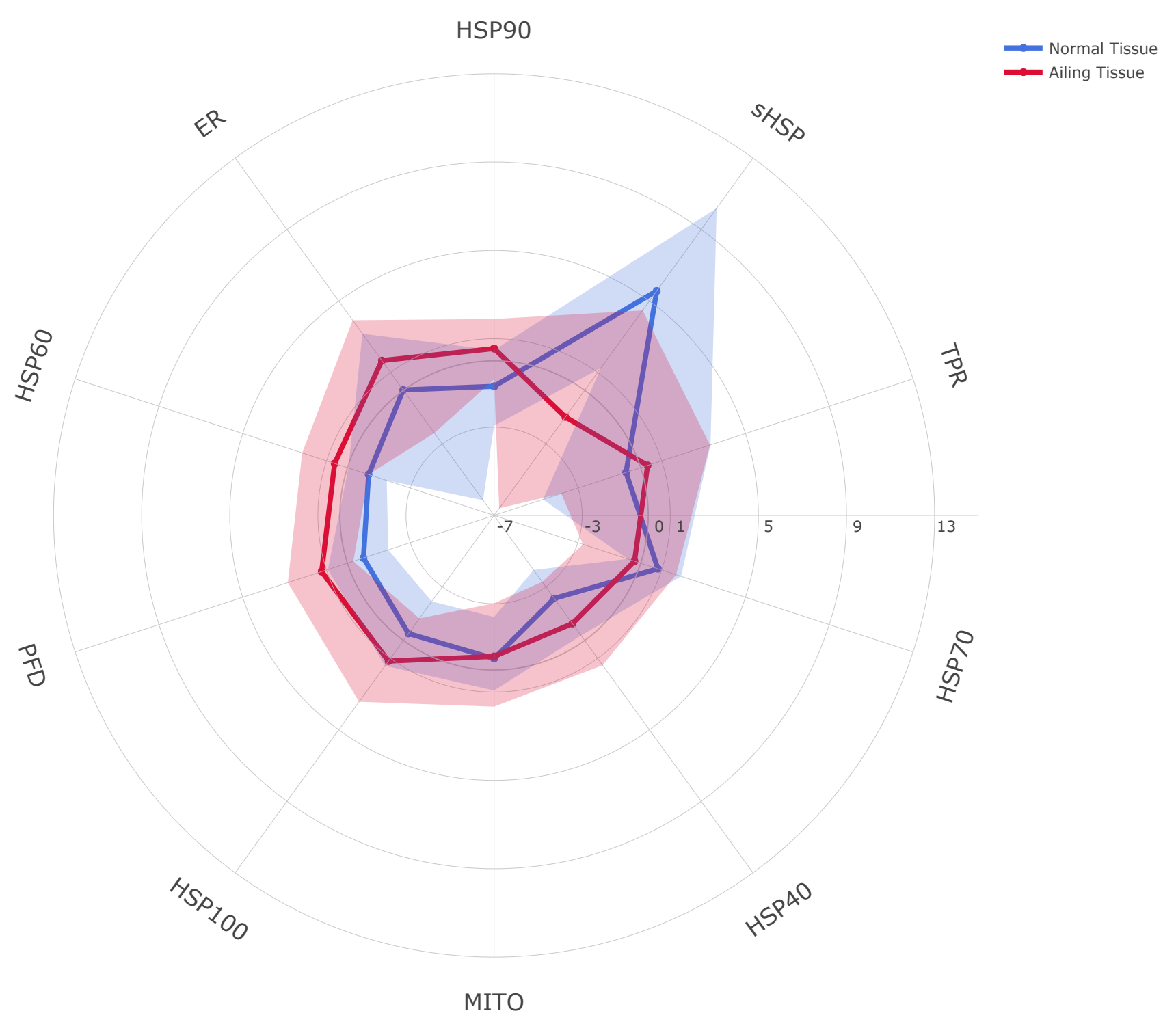




\section{Breastinvasivecarcinoma}

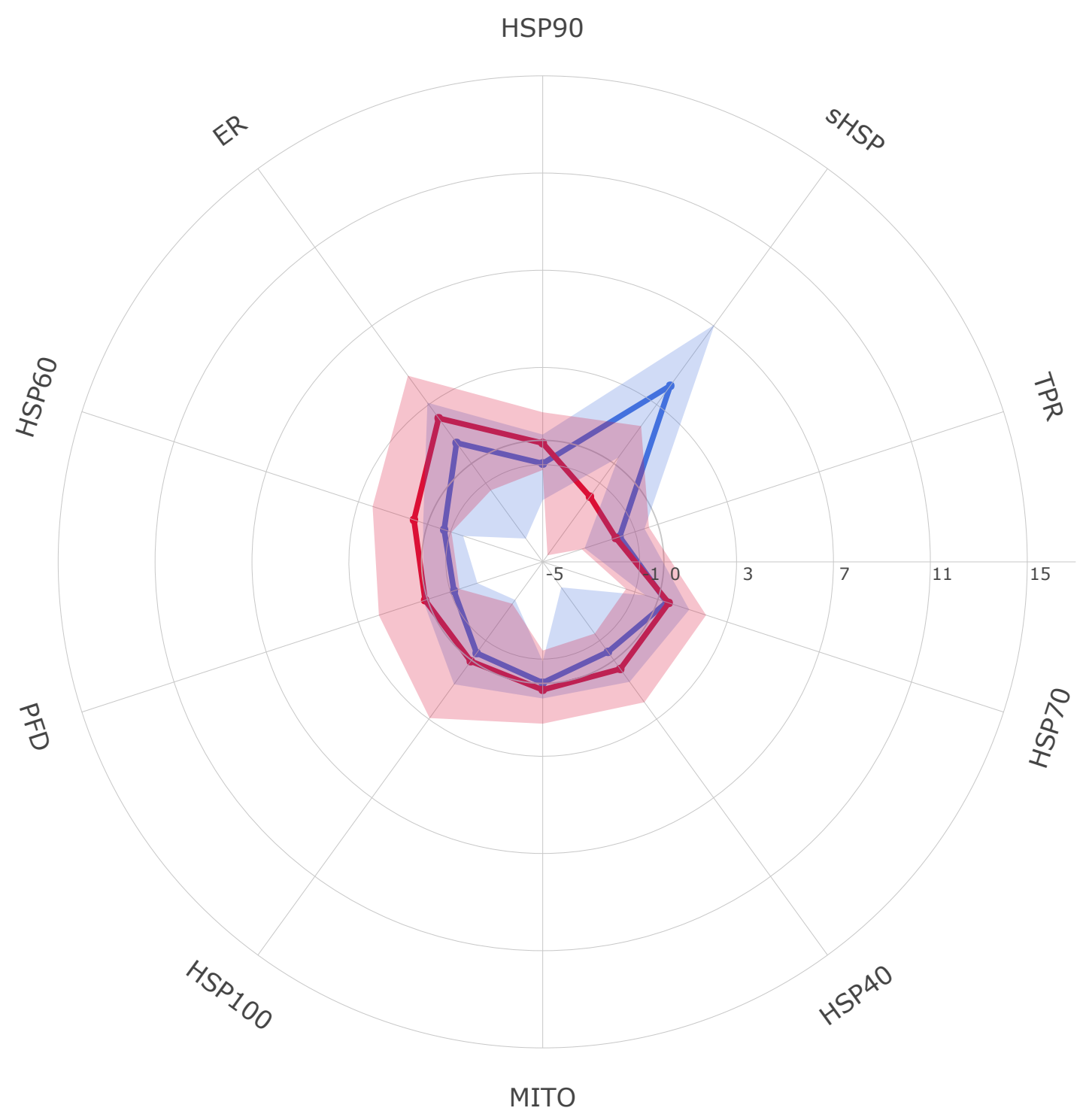


Cervicalsquamouscellcarcinomaandendocervicaladenocarcinoma

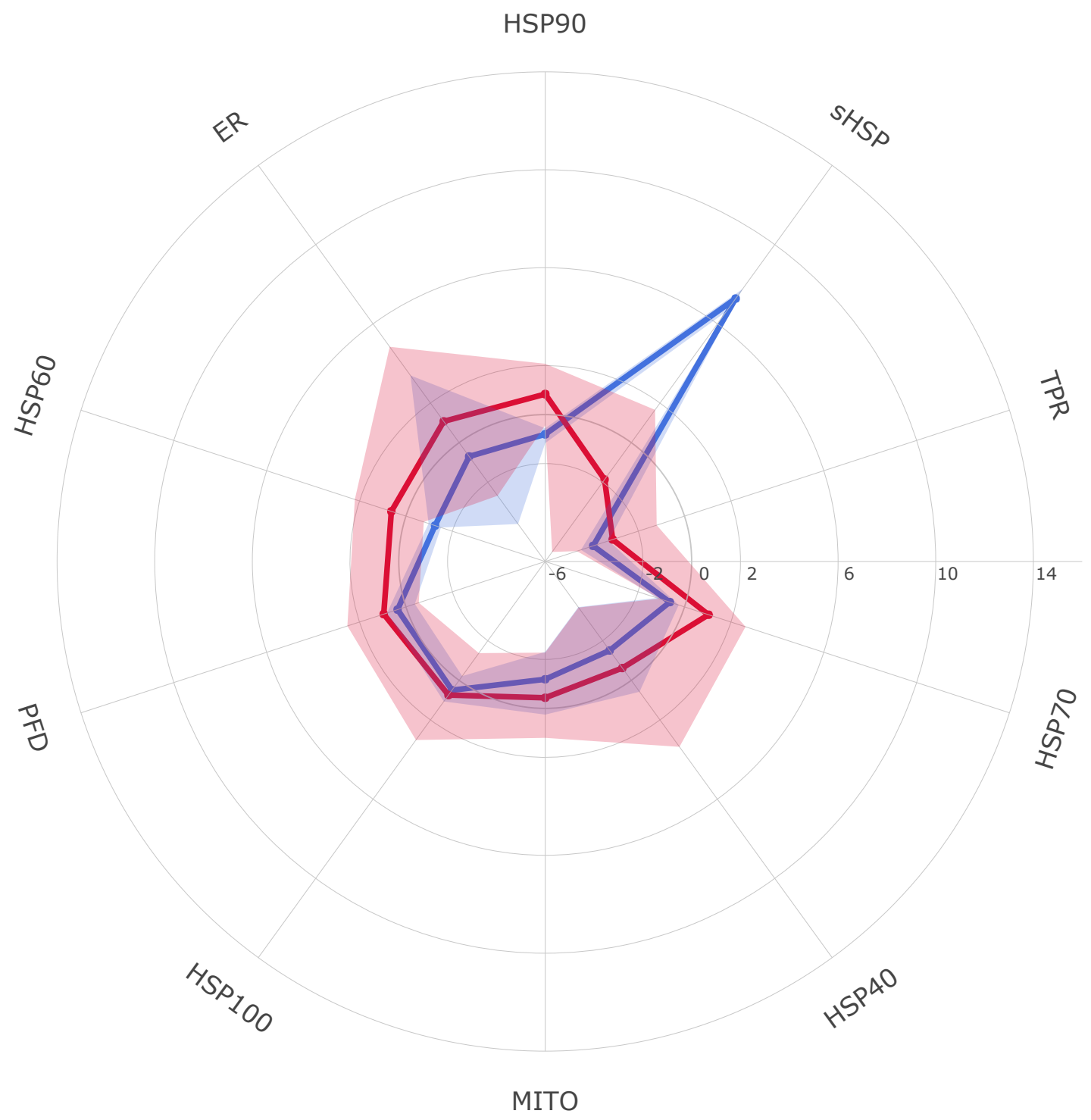




\section{Cholangiocarcinoma}

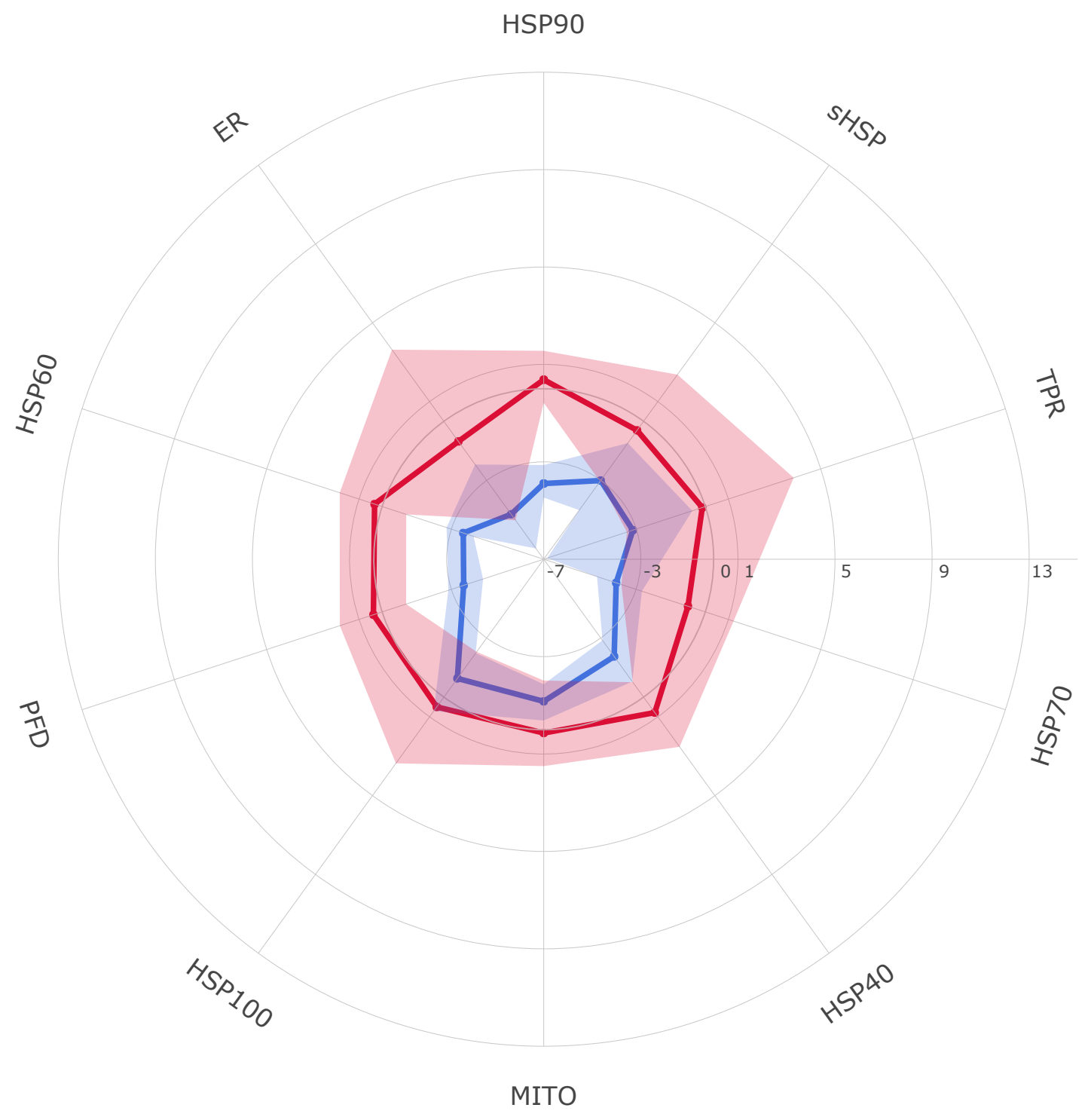


Esophagealcarcinoma

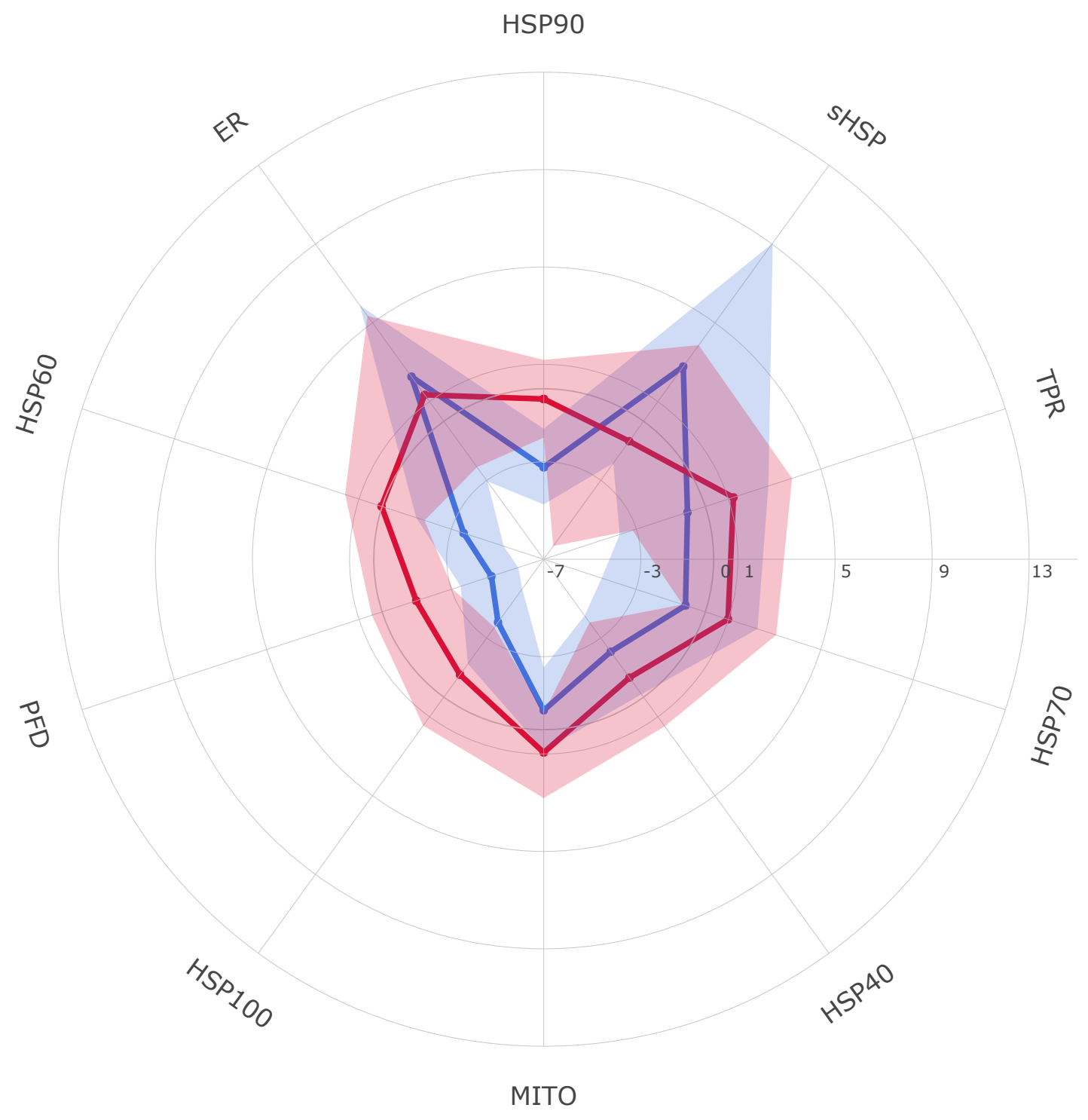




\section{Glioblastomamultiforme}

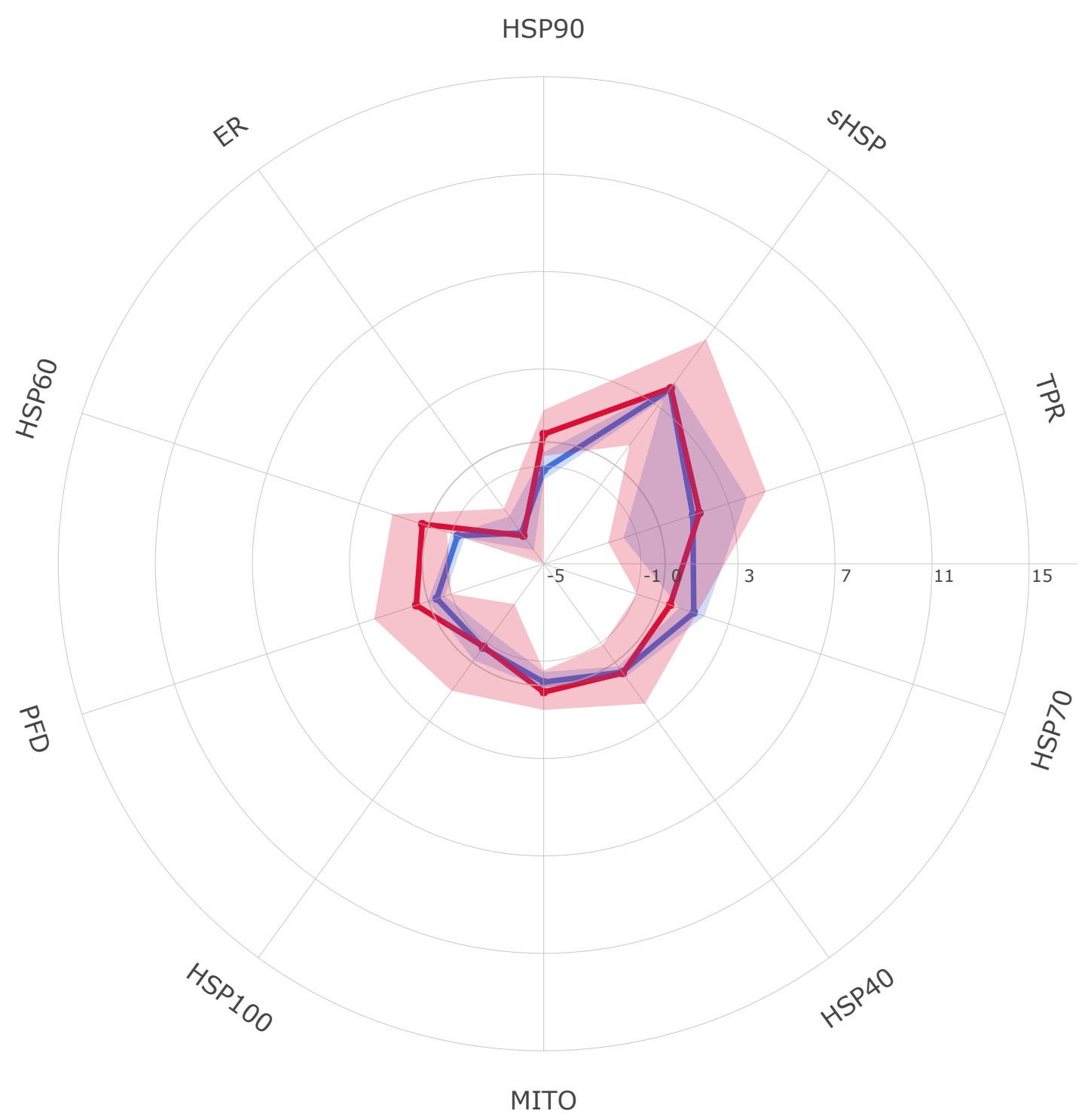


Headand Necksquamouscellcarcinoma

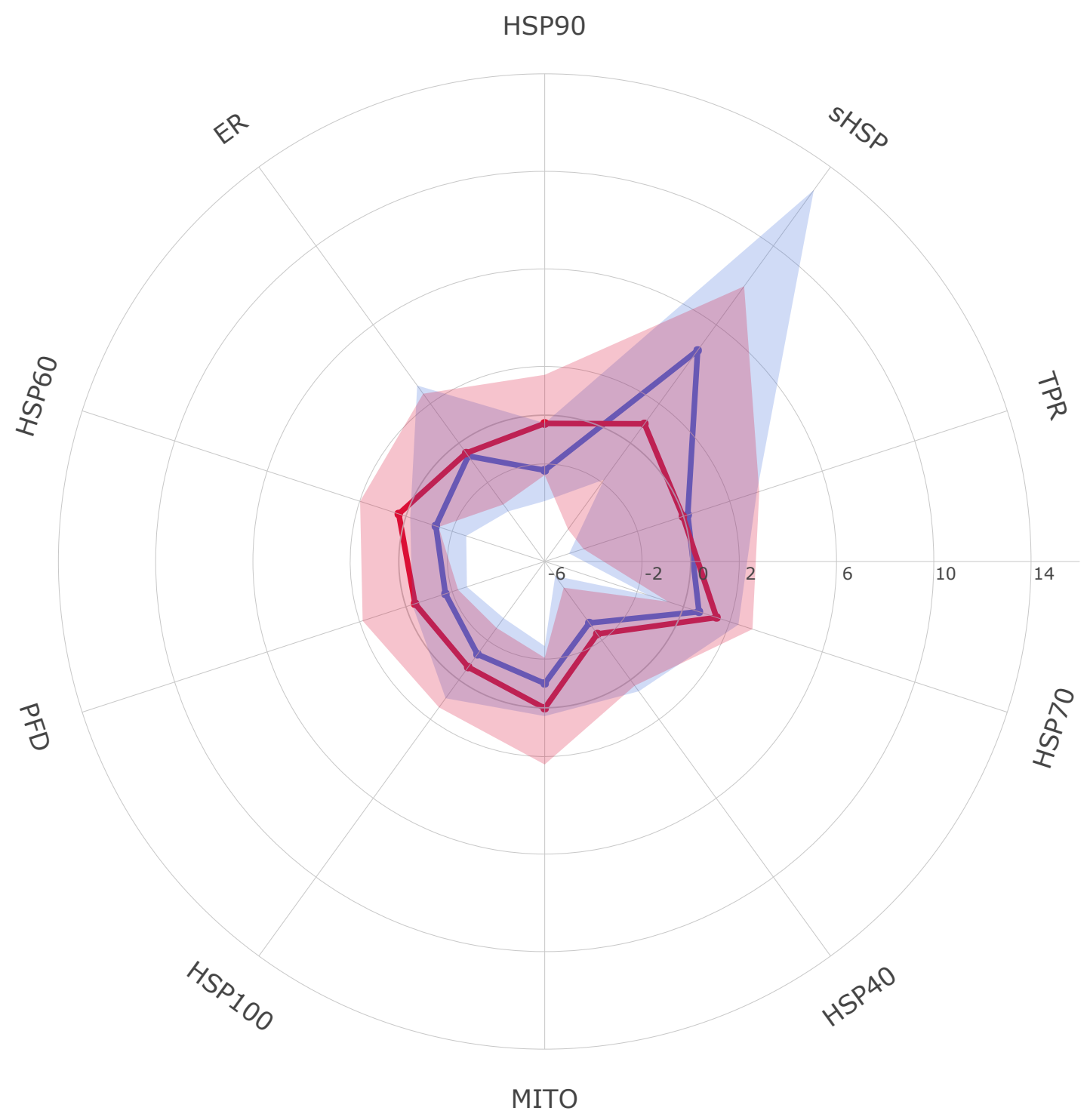




\section{Kidney Chromophobe}

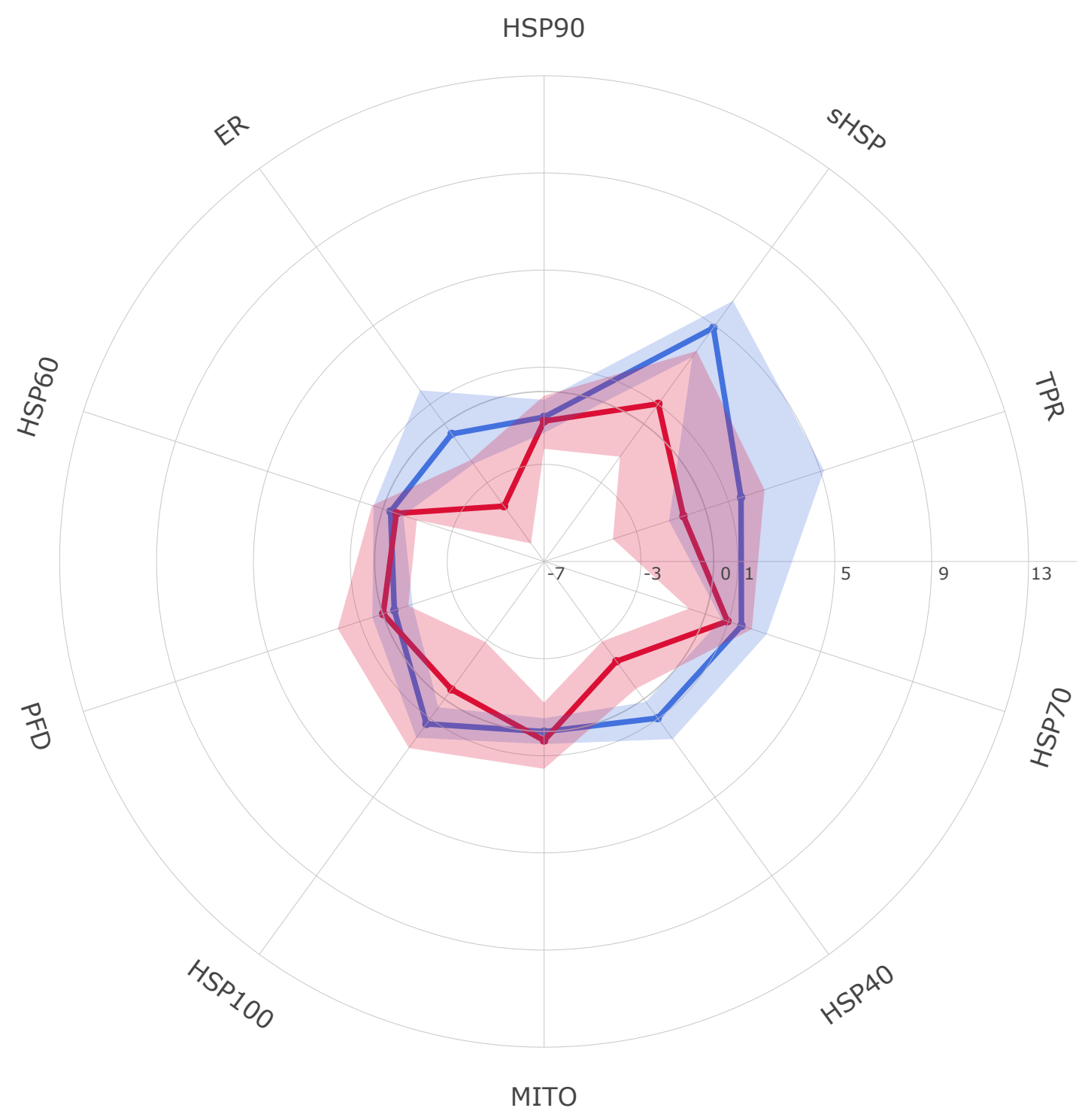


Kidneyrenalclearcellcarcinoma

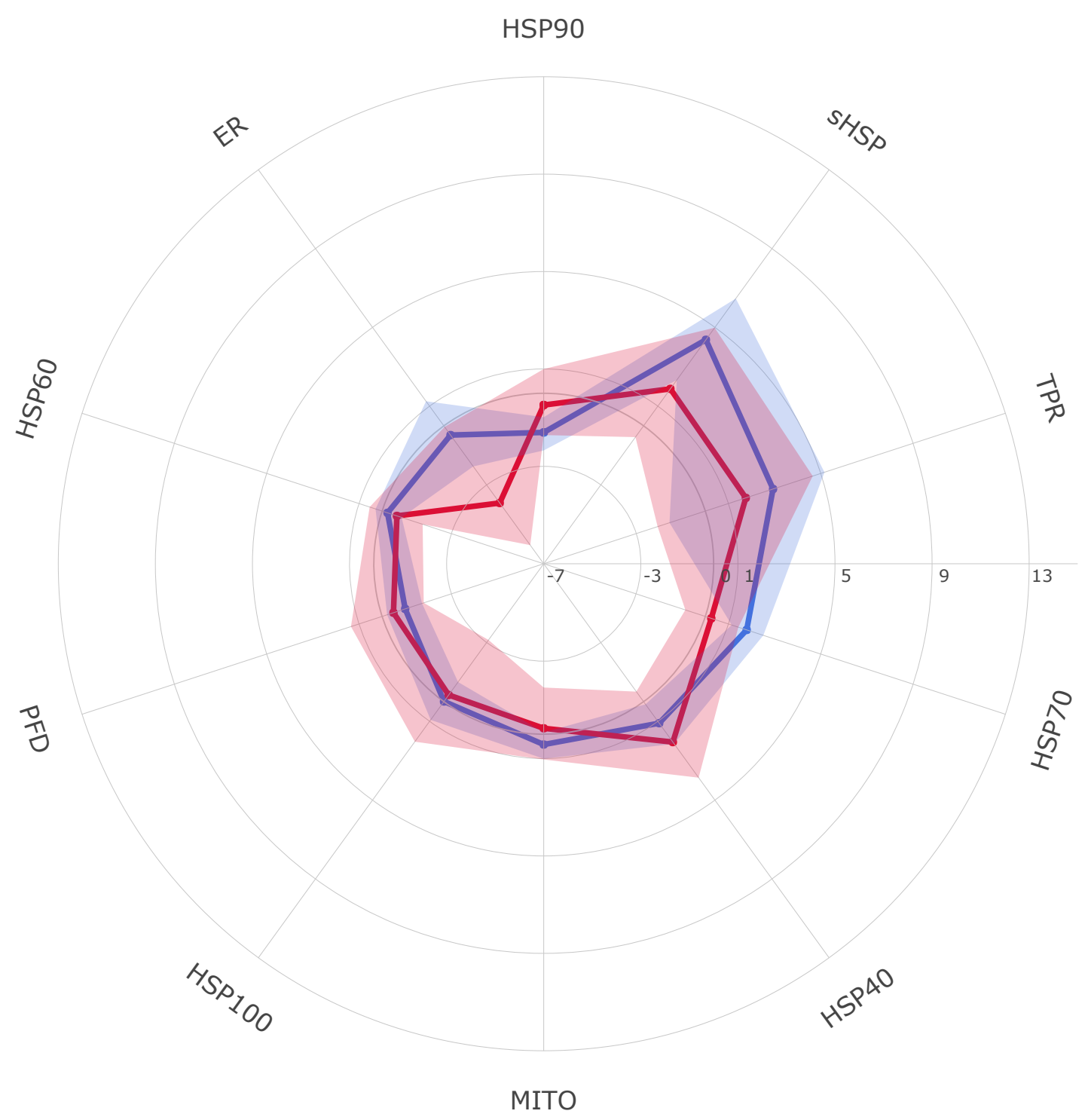




\section{Kidneyrenalpapillarycellcarcinoma}

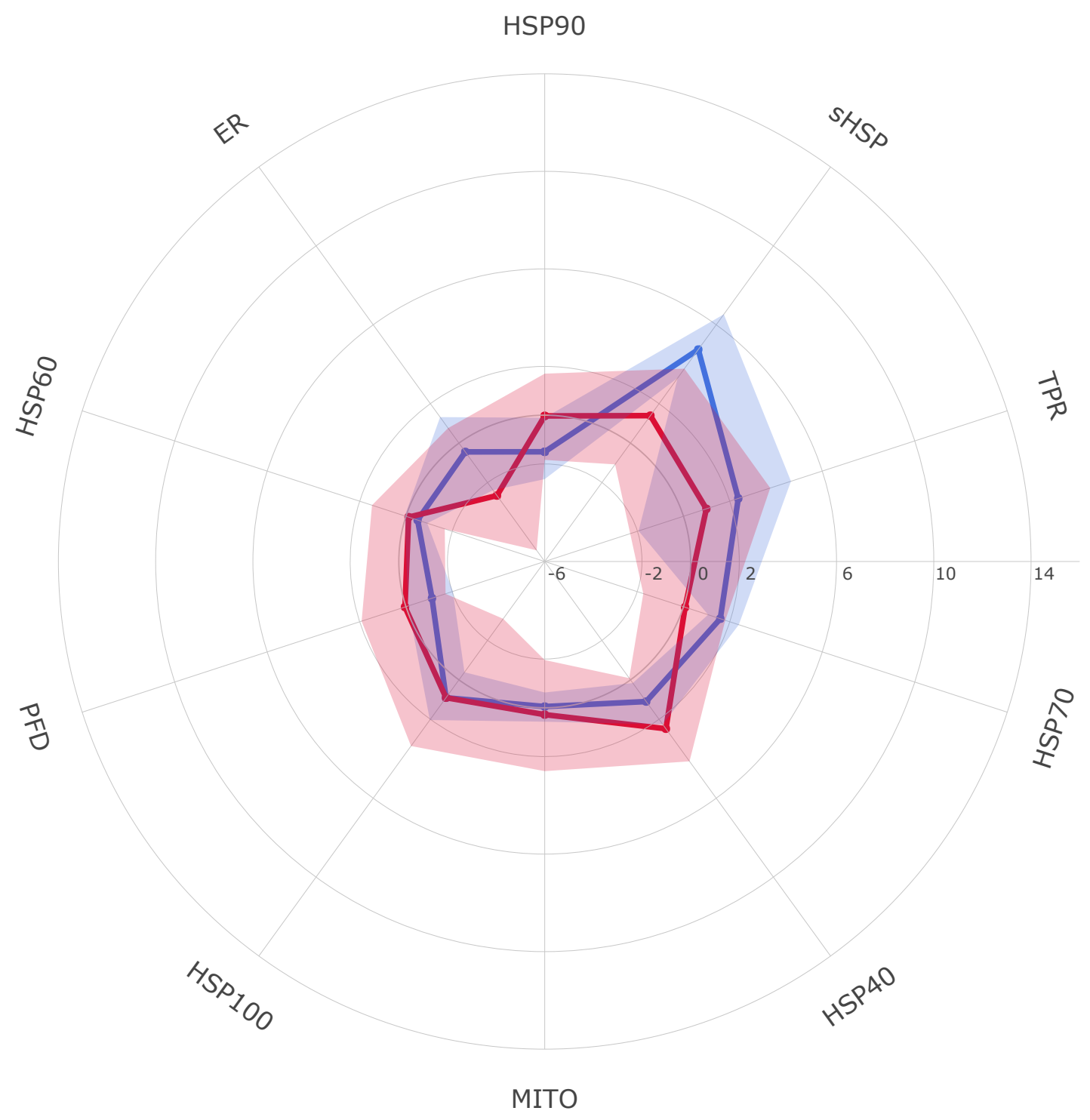


Liverhepatocellularcarcinoma

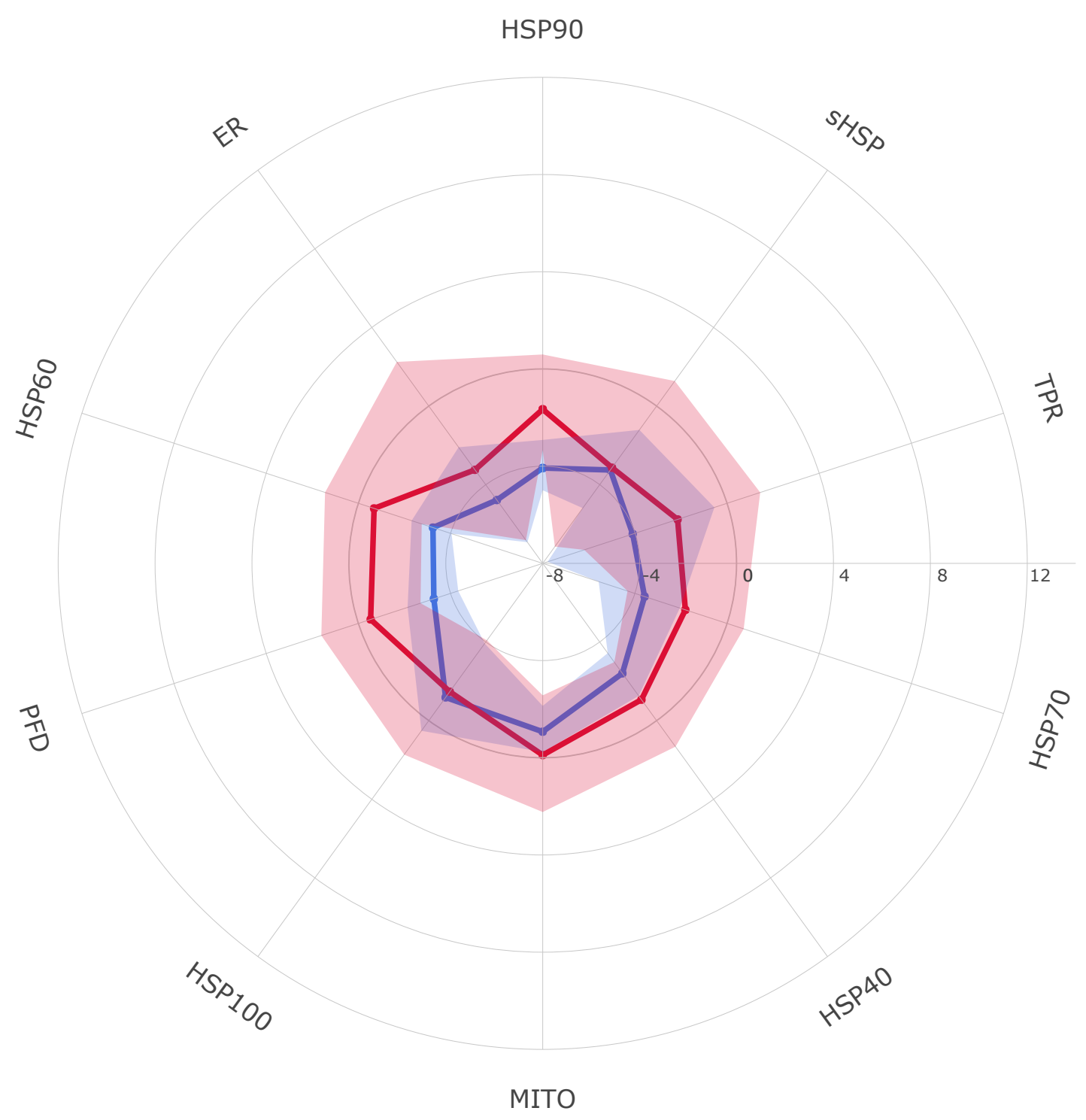




\section{Lung Adenocarcinoma}

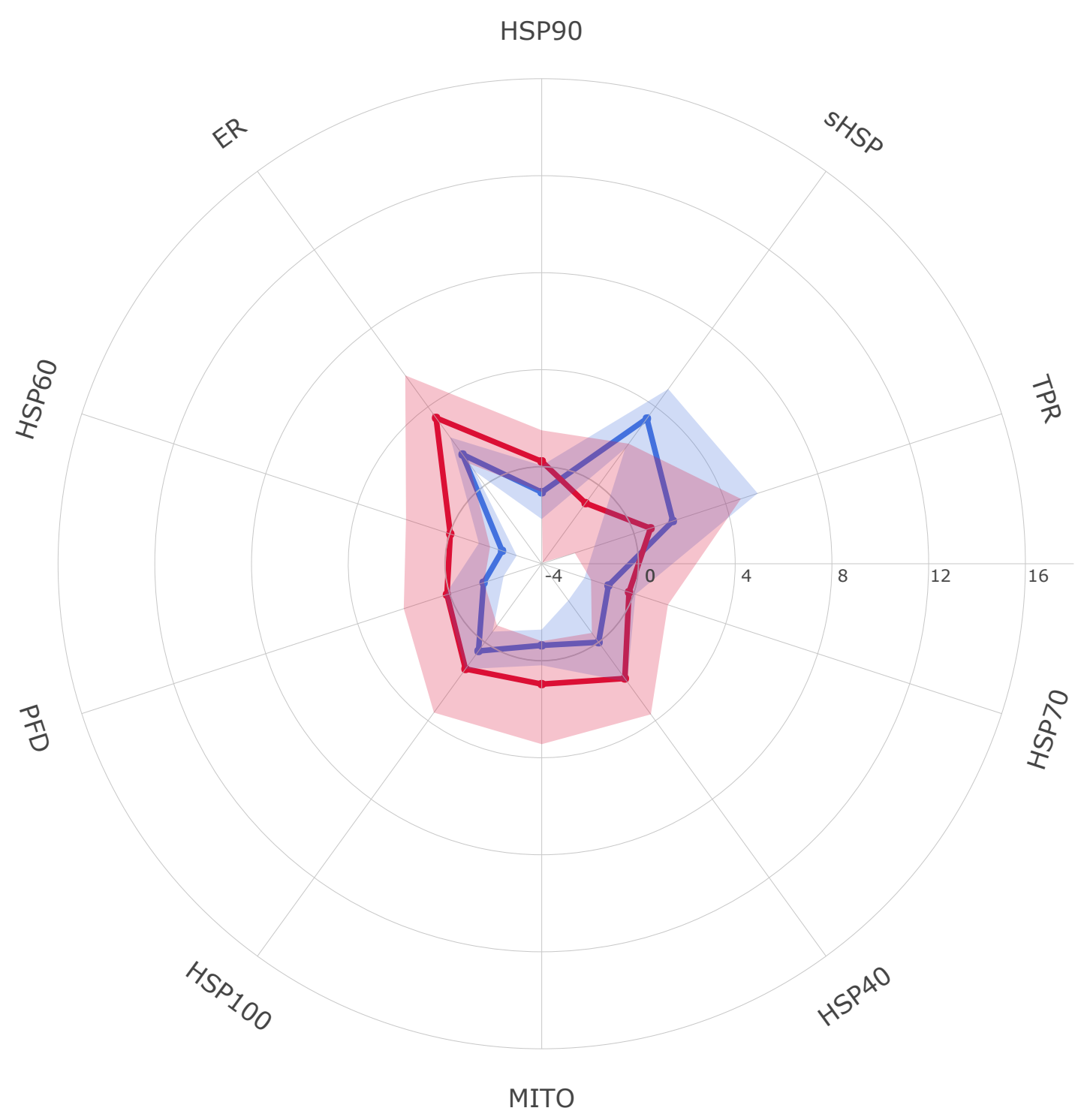




\section{Lungsquamouscellcarcinoma}

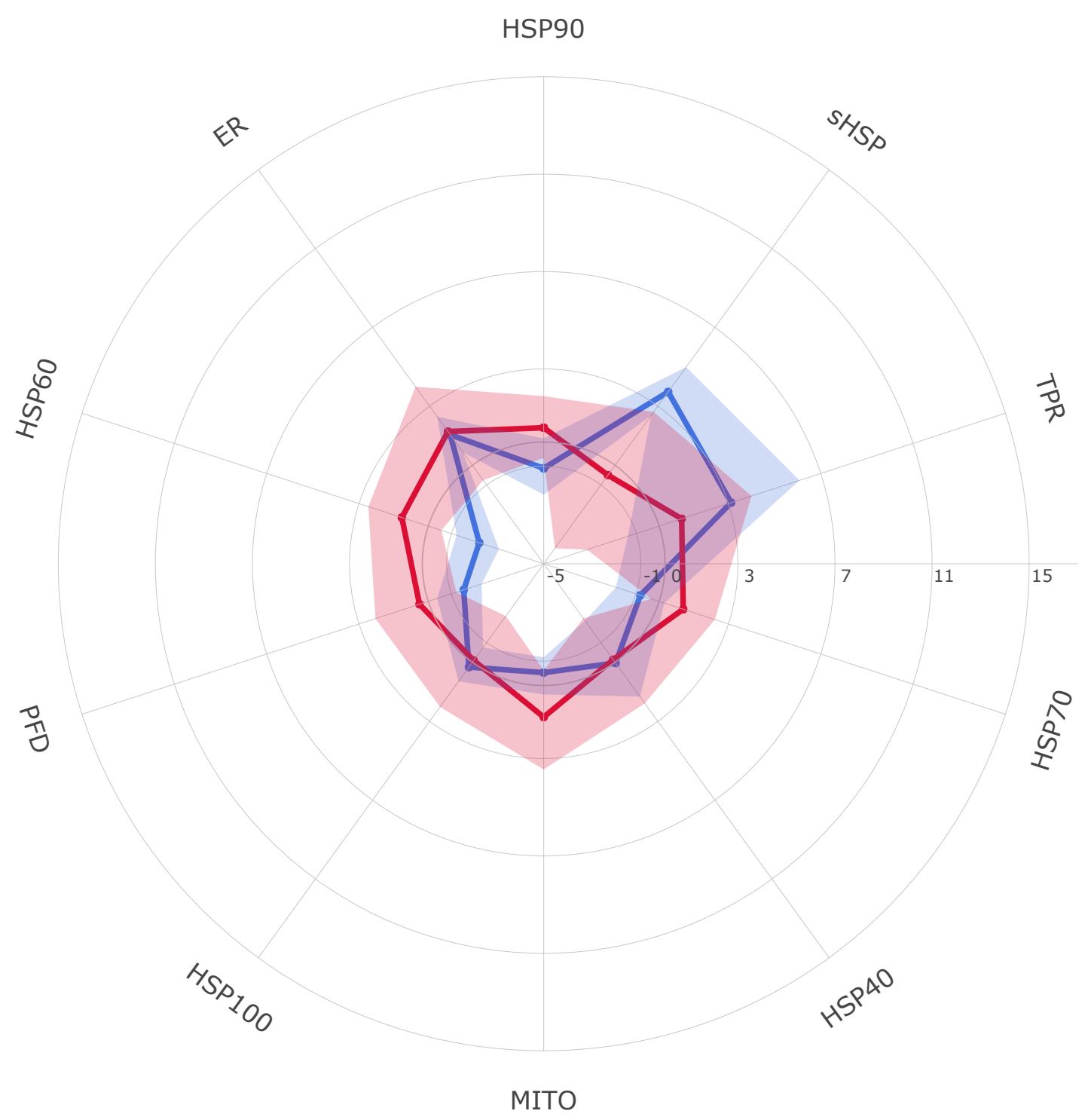




\section{Pancreaticadenocarcinoma}

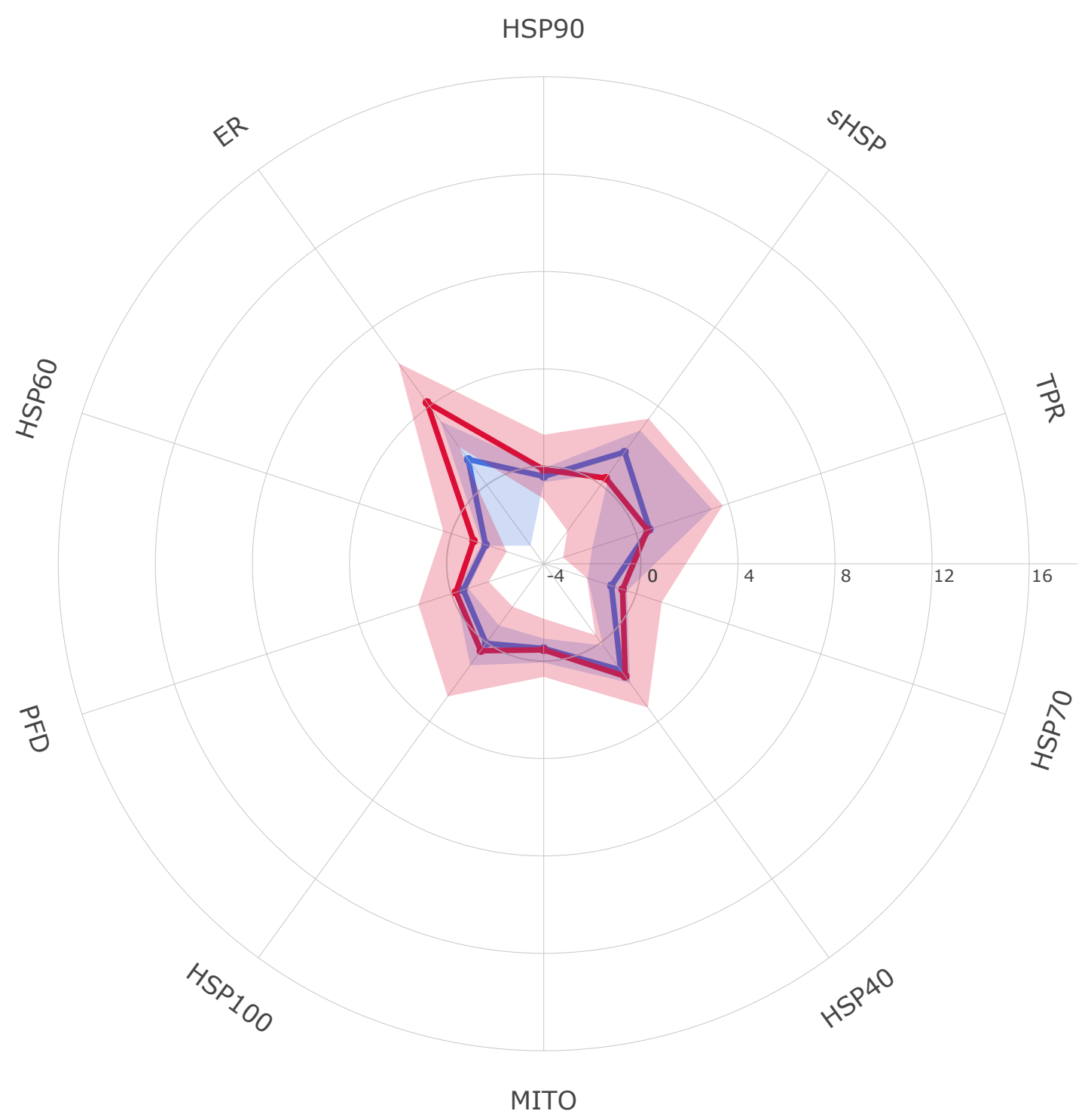




\section{Pheochromocytomaand Paraganglioma}

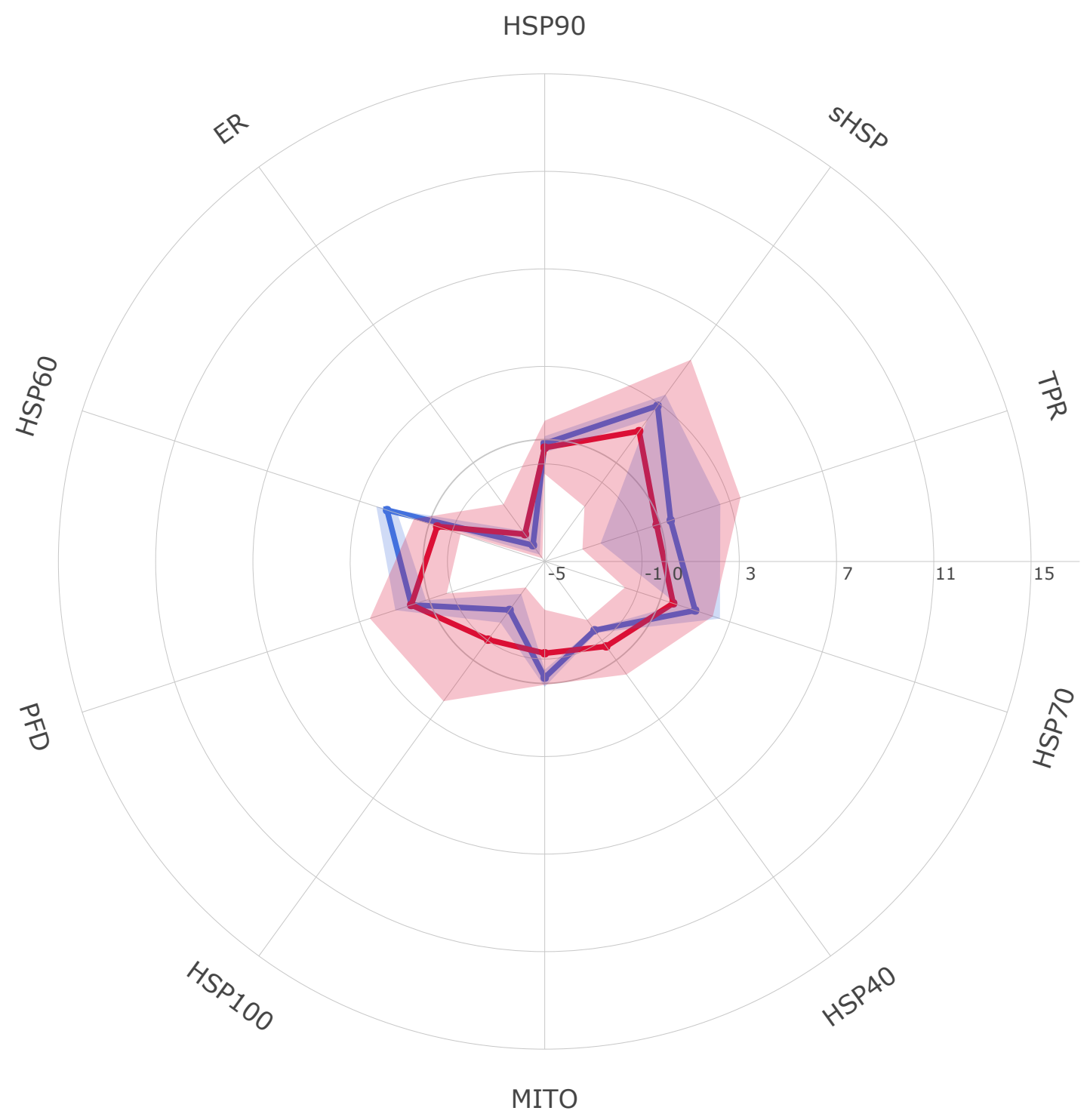




\section{Prostateadenocarcinoma}

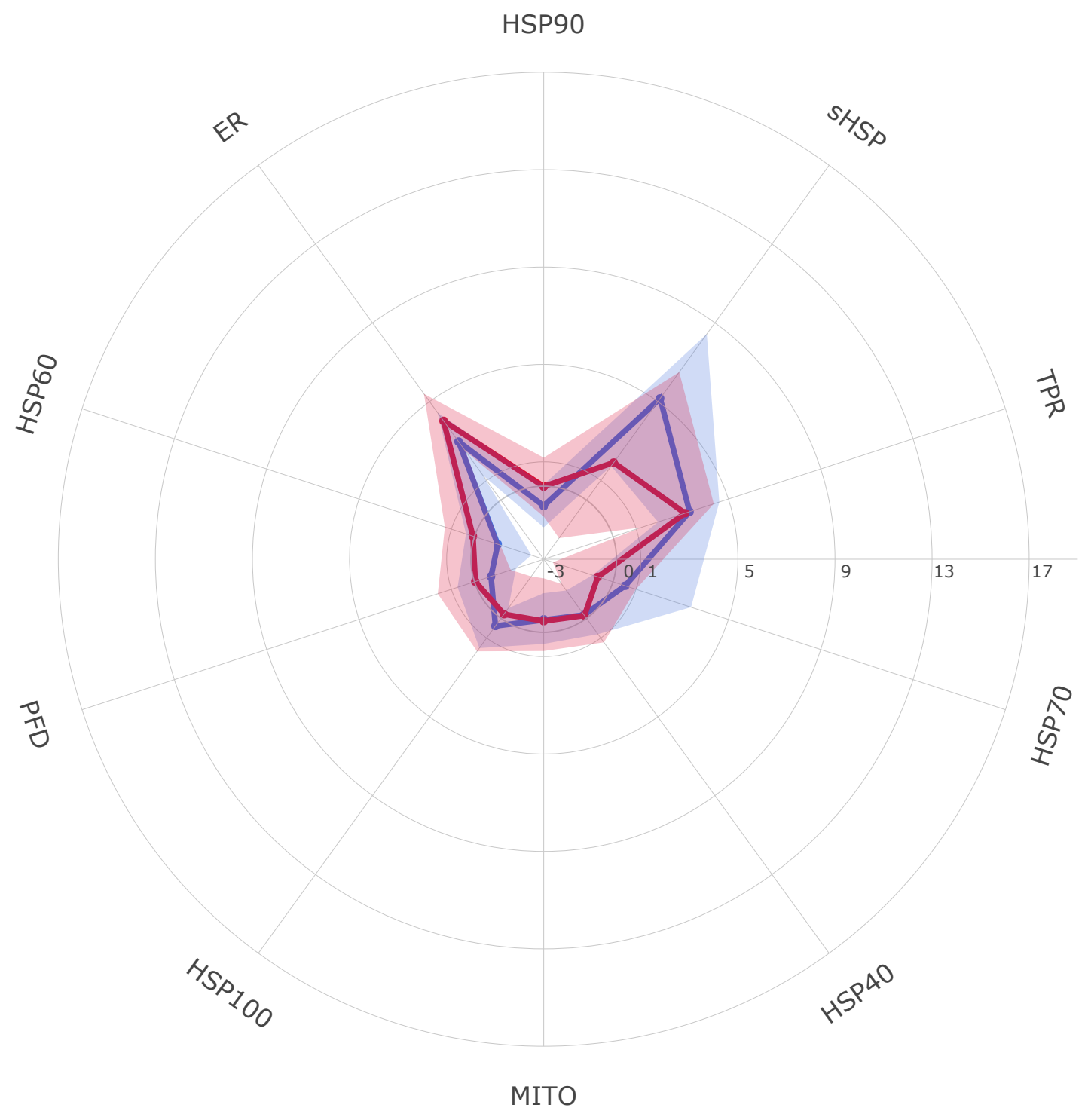




\section{Sarcoma}

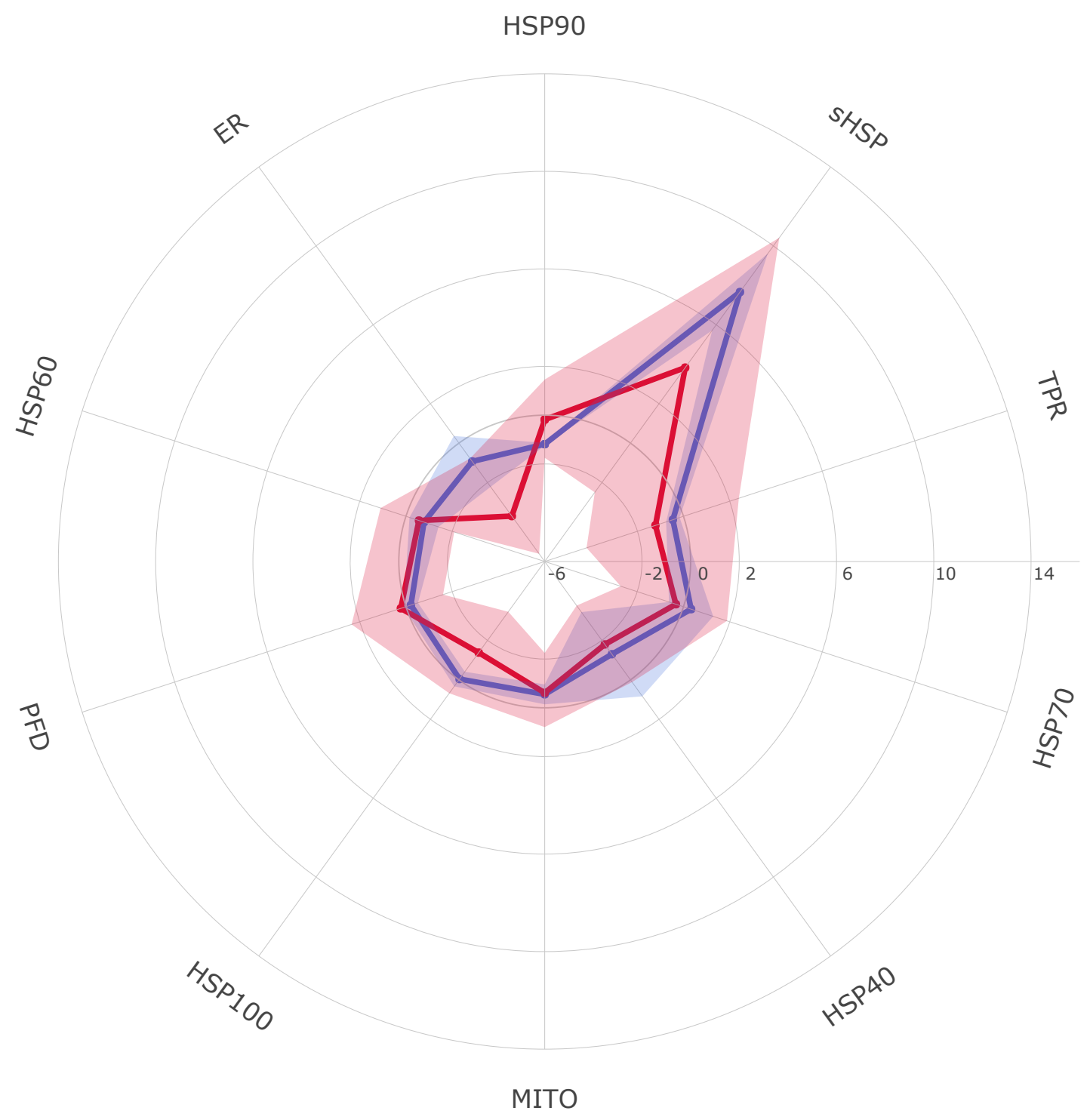


Skin Cutaneous Melanoma

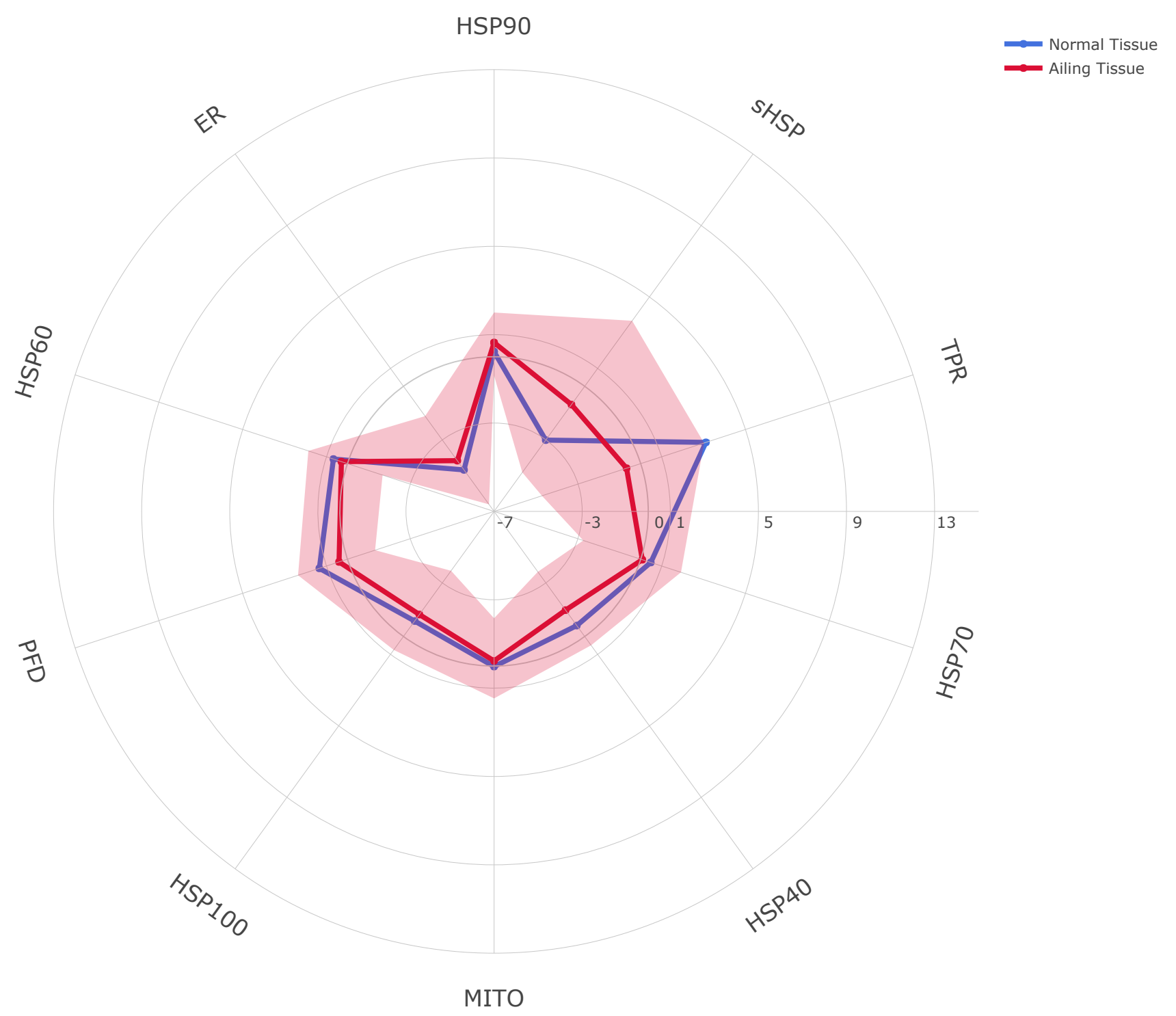


Stomachadenocarcinoma

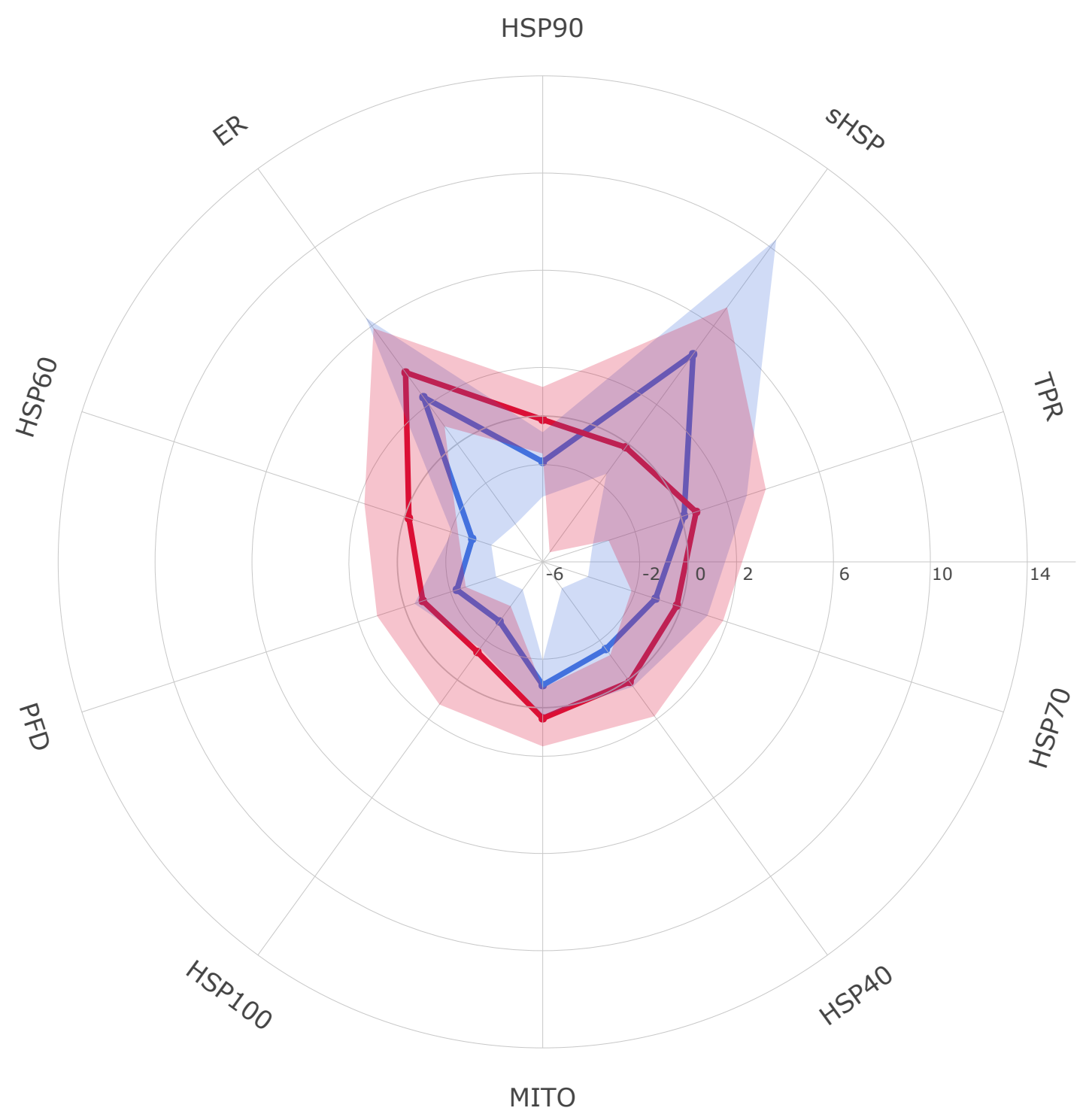




\section{Thymoma}

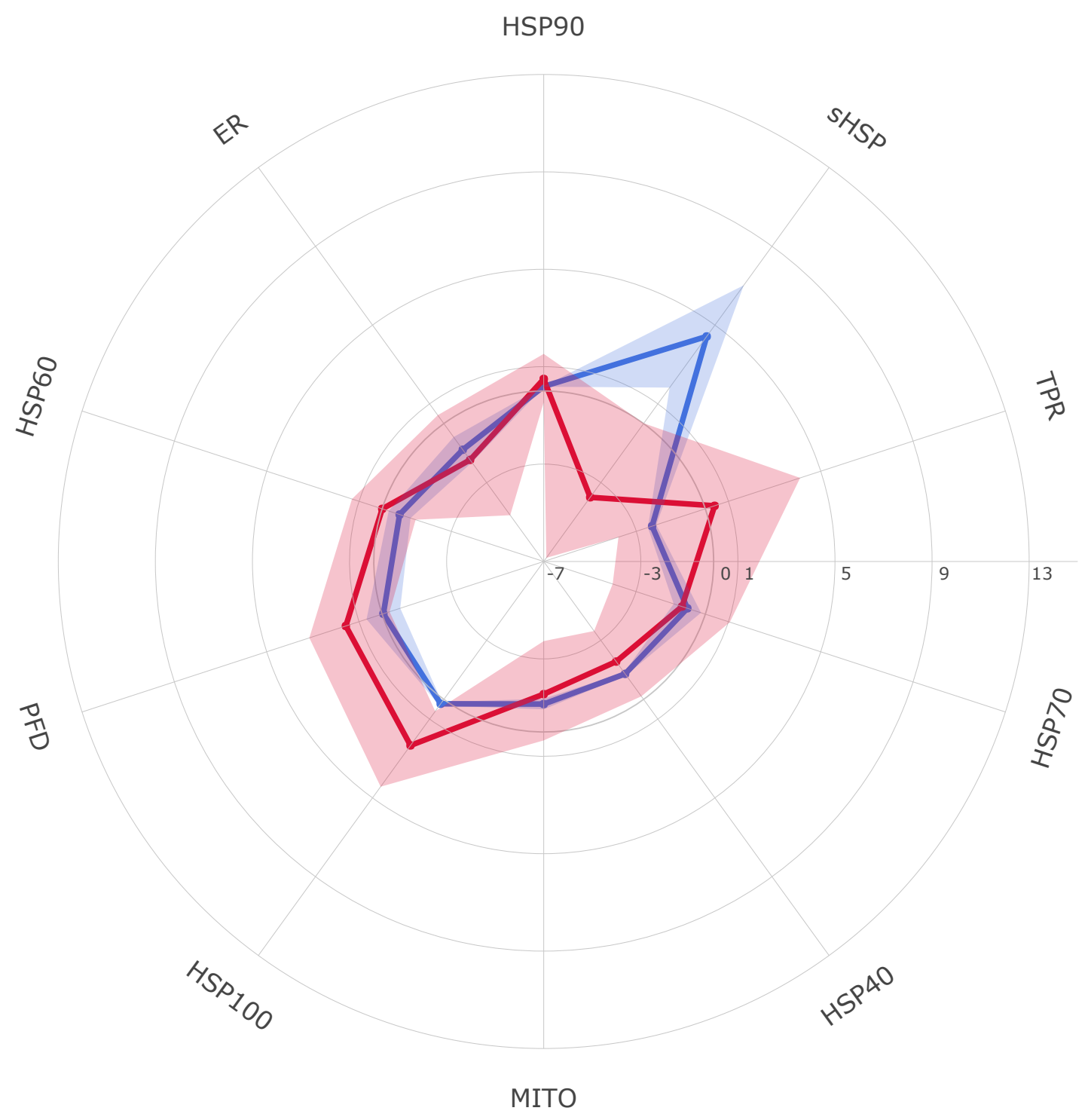


Thyroidcarcinoma

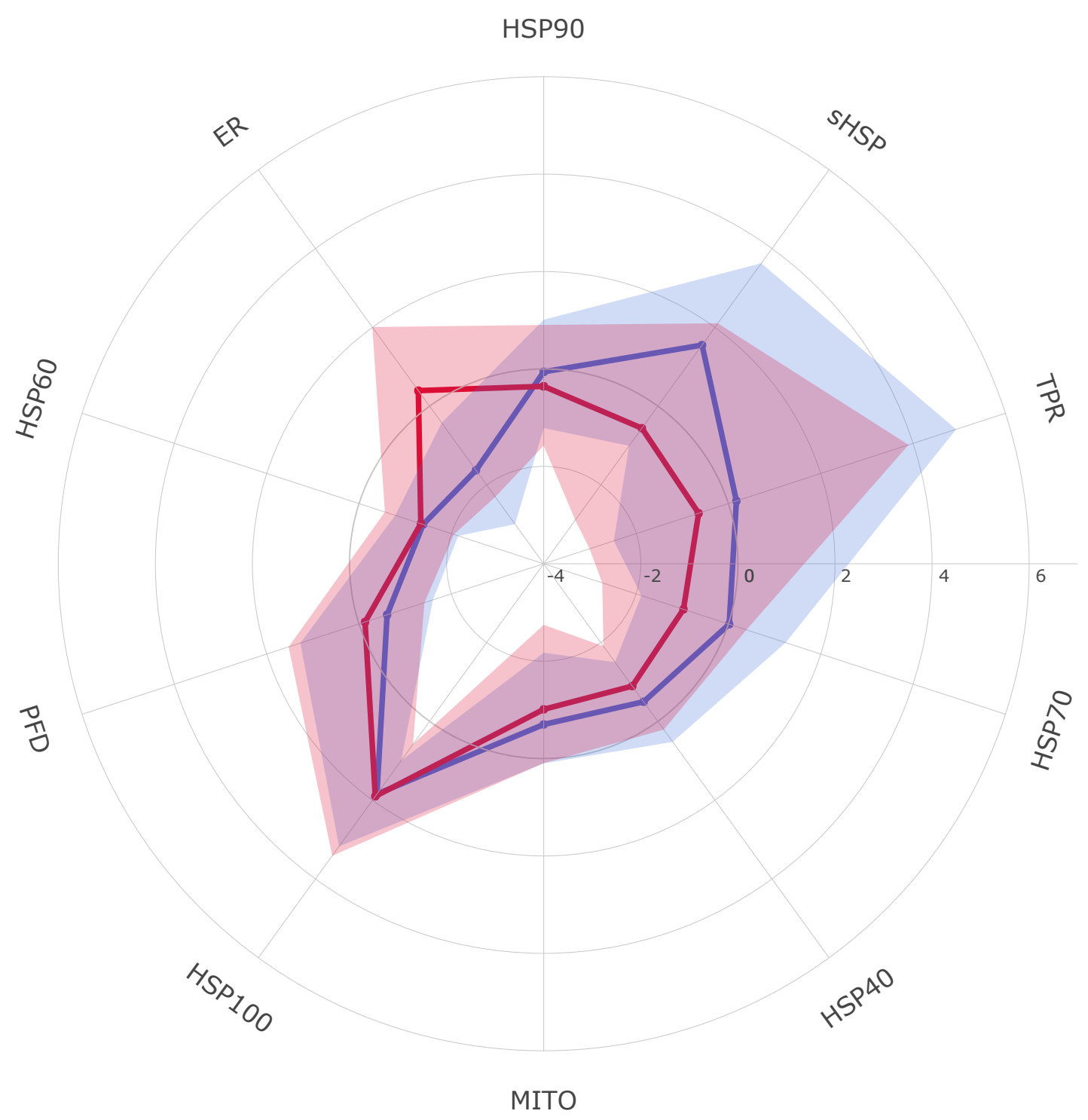




\section{Uterine Corpus Endometrial Carcinoma}

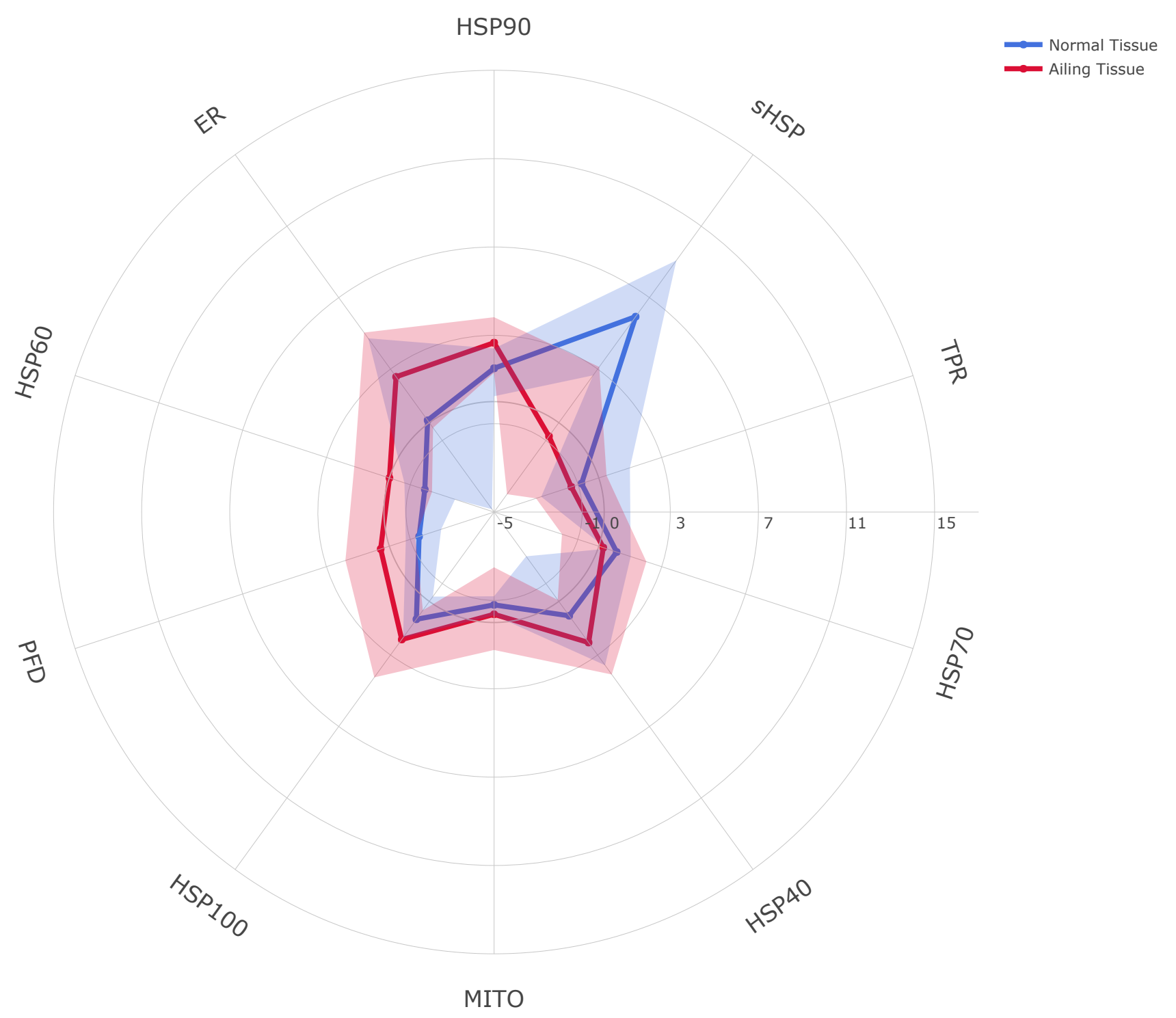




\section{Alzheimer Disease}

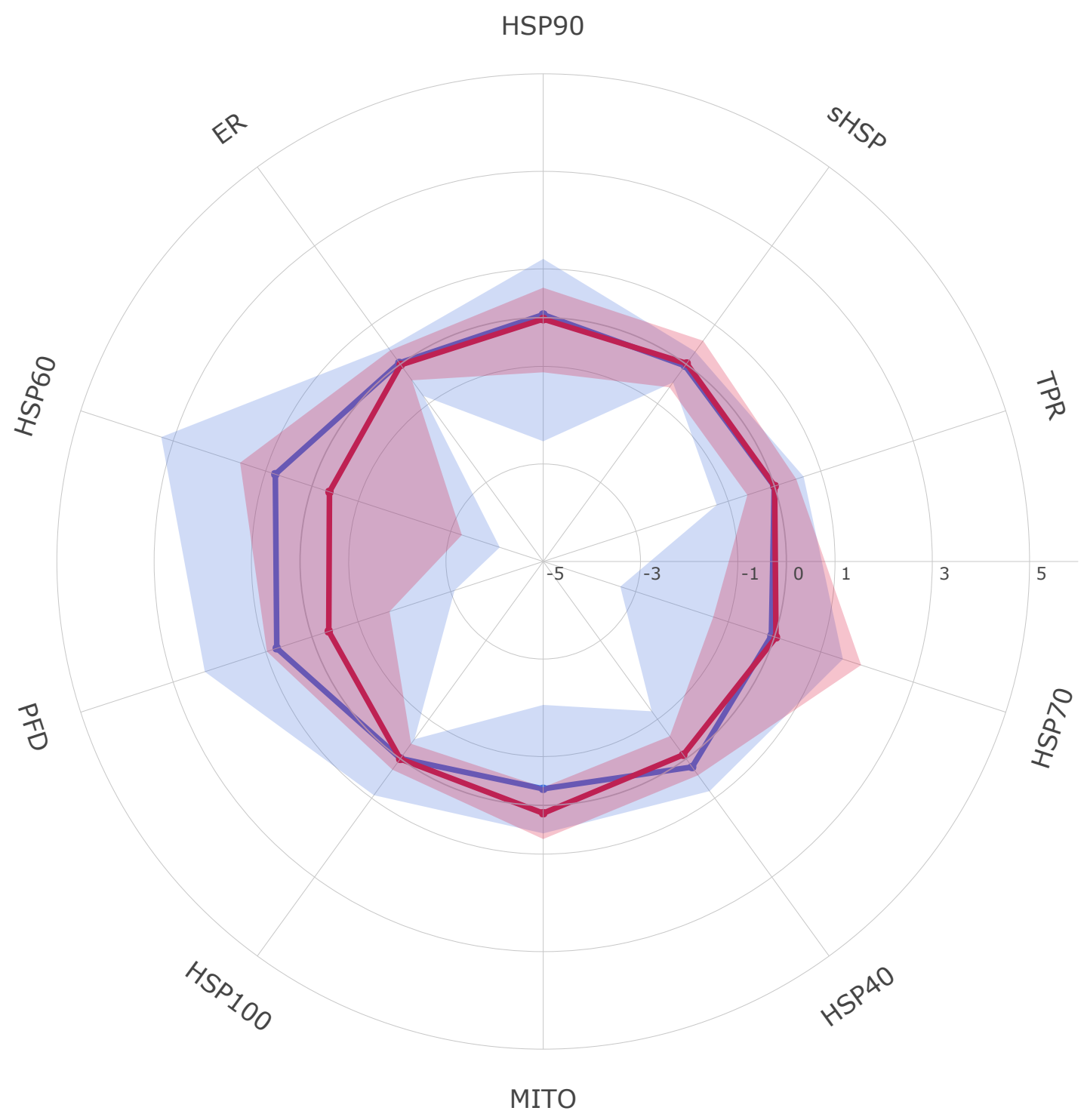


Huntington Disease

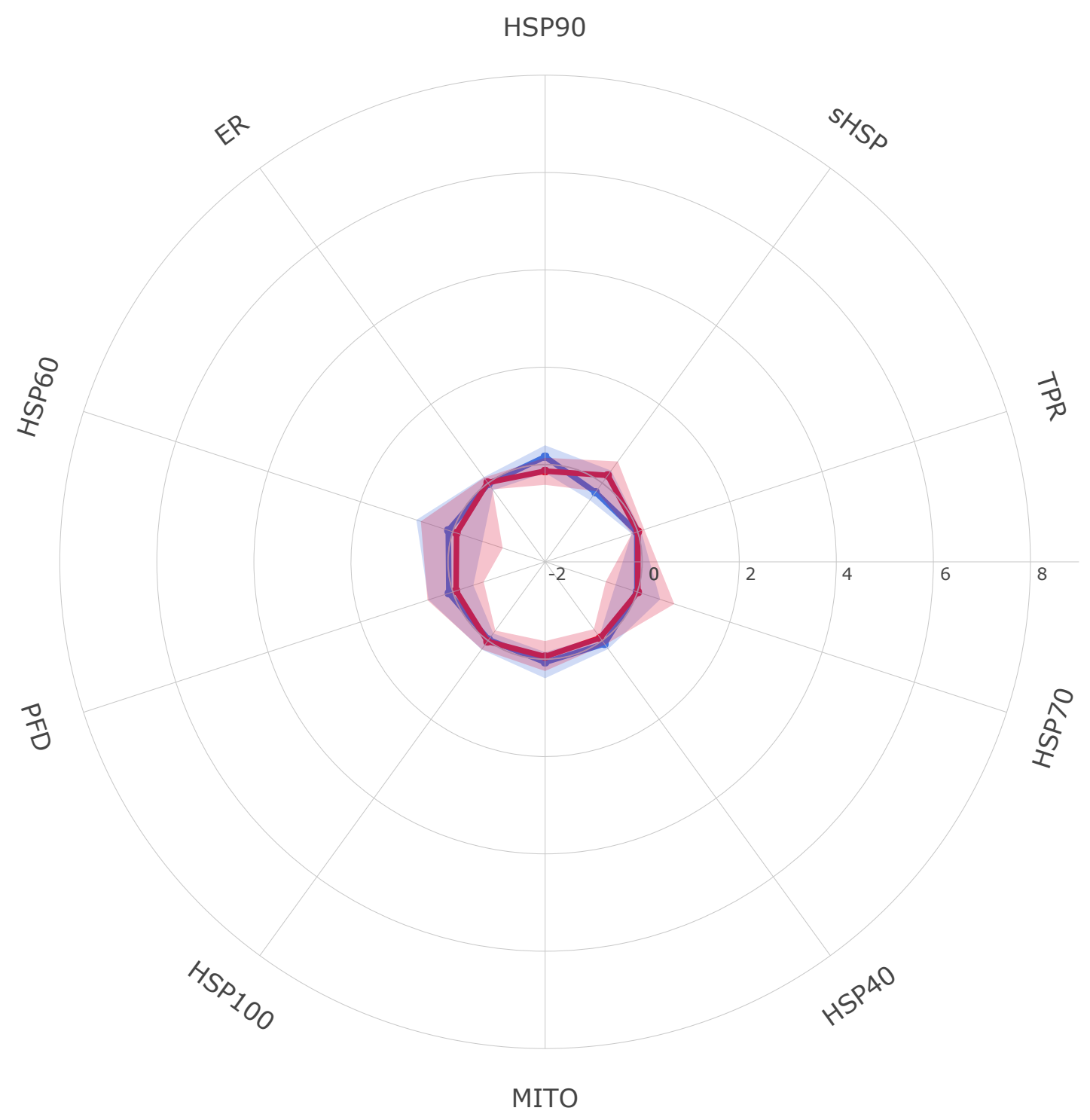




\section{Parkinson Disease}

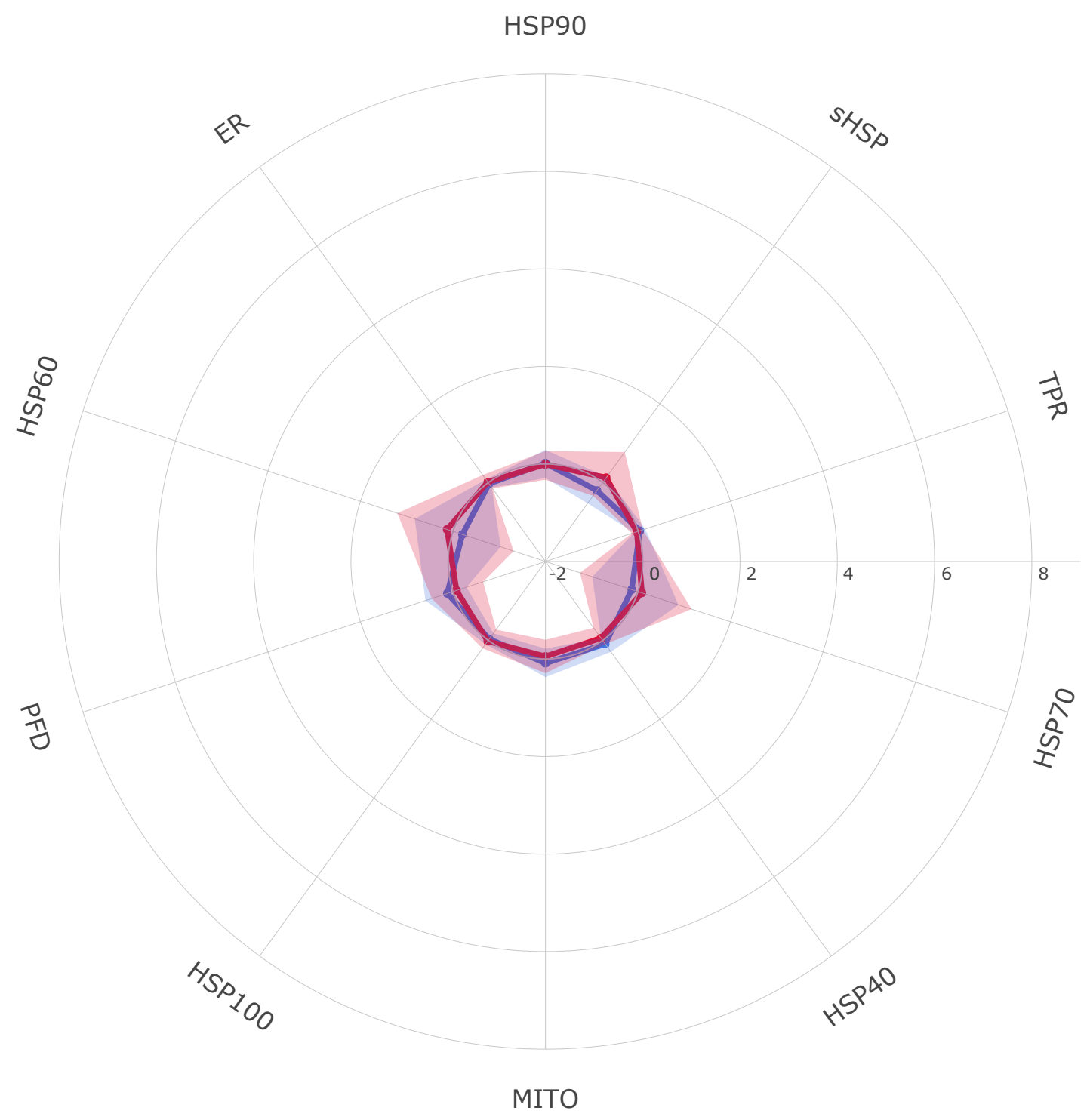

